\title{
DENDRITIC CELLS COMMIT T-CELLS TO A TOLERANT PHENOTYPE IN TOLERANT LUNG TRANSPLANT RECIPIENTS
}

\author{
K. Botturi*, Y. Lacoeuille*, P. Thomas*, M. Reynaud-Gaubert* and A. Magnan*
}

Lung Transplantation Best Abstract Award, sponsored by Novartis Pharma Schweiz AG, Roche Pharma AG, Vitrolife Sweden

\author{
*UPRES EA 3287, Faculté de Médecine, Université de la Méditerranée, Marseille \\ ${ }^{\#}$ IFR Jean Roche, EA 2201, Marseille, France
}

WINNING ABSTRACT: Immune characteristics distinguishing tolerant lung transplant recipients (LTR) from patients with Bronchiolitis obliterans syndrome (BOS) are largely unknown. We compared the effect of dendritic cells (DC) on T-cell activation in healthy LTR (non BOS) and in BOS patients.

30 Non BOS and 14 BOS recipients were studied. Mature dendritic cells were derived from blood monocytes and co-cultured with autologous T cells at various ratios. T cell CD69, CD25, CD28, ICOS and CTLA-4 expression and IL-4, IL-13, IFN- $\gamma$, and IL-10 production were assessed by flow cytometry. Dendritic cell expression of surface markers and indoleamine 2,3 dioxygenase was also studied. Experiments were repeated in presence of $P$. aeruginosa or anti-CTLA-4 antibodies.

In dendritic cell/LT co-cultures, T cell CD69, CD28 and ICOS decreased in non BOS ( $<0.03)$. By contrast, CD4 ${ }^{+}$CD25 $5^{\text {high }}$ T regulatory cells (Treg), CTLA4 expression and IL-10 production increased $(p<0.05)$. II-13 and IL-4 decreased in non BOS only $(p<0.03)$, whereas IFN- $\gamma$ did not vary. The increase in dendritic cell/LT ratio induced a decrease in T-cell activation in non BOS, with inverse result in BOS. Compared to BOS, dendritic cells from non BOS displayed a down-modulation of CD83, CD80 and higher levels of IDO $(p<0.05)$. Stimulation by $P$. aeruginosa did not remove tolerogenic effect of dendritic cells on non BOS T-cells. Finally, decreased Treg and expression of IL-10 were detected when adding anti-CTLA-4 in non BOS ( $<<0.05$ ) but not in BOS.

In contrast with BOS recipients, dendritic cells from non BOS induce a tolerant T cell phenotype, by using CD80/CD86CTLA4 axis.

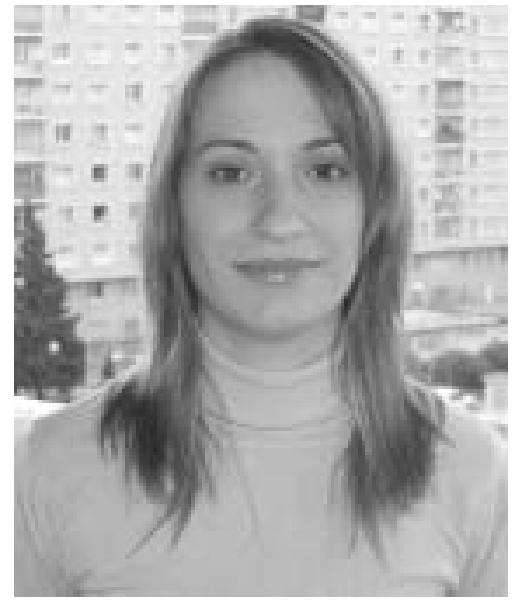

Karine Botturi

UPRES 3287, Pathologie Respiratoire Liée à

l'Environnement, Faculté de Médecine, Marseille, France

\section{MY JOB AND THE UNIT IN WHICH I WORK}

I am currently working as a PhD fellow at Antoine Magnan's Laboratory (Equipe d'Accueil 3287, “Environment-related respiratory diseases") at the Marseille Medical School,

STATEMENT OF INTEREST: None declared.
Marseille, France. The laboratory is involved in immune studies in humans. It closely collaborates with the chest medicine dept of the University Hospital in Marseille, which has long been recruiting cohorts of patients with chronic bronchial diseases, such as asthma (headed by Professor Daniel Vervloet) and lung chronic rejection (headed by Professor Martine Reynaud-Gaubert and Dr Pascal Thomas).

I began my $\mathrm{PhD}$ in 2004, studying the immunological mechanisms leading to chronic lung rejection and asthma, under the supervision of Professor Antoine Magnan. With two papers, including the work presented below, I successfully defended my thesis in November 2007, and qualified as a PhD. I then relocated to the Institut du Thorax in Nantes, where I am currently extending our cohorts to other university hospitals in the frame of multicentric projects.

\section{MY WINNING POSTER AS PART OF MY RESEARCH}

The winning abstract covers part of my $\mathrm{PhD}$ research, and focuses on immune mechanisms of chronic lung rejection. Chronic lung rejection consists of the occurrence of progressive pulmonary failure due to bronchiolitis obliterans syndrome (BOS), and remains the major cause of long-term lung allograft loss. BOS results from an unclear immune process occurring at some point after surgery, in the absence of donor's immune cells [1]. We hypothesised that the immune characteristics of autologous dendritic cells and their effects on T-cell interactions differ in patients compared with healthy lung transplant recipients. Consecutive lung transplant recipients belonging to 
the Marseille cohort were recruited. They were routinely investigated with lung function tests and bronchoalveolar lavage, and blood samples were collected at the clinic. Samples were transferred to the laboratory were I perform the following experiments: monocyte isolation, culture and dendritic cell differentiation, T-cell activation studies and cytokine detection at the single cell level, either with or without dendritic cell costimulation. The main results indicate that autologous monocyte-derived dendritic cells from healthy recipients differentiate into an immature phenotype, driving T-cells to demonstrate tolerant properties; this occurs as an intrinsic characteristic of the dendritic cells' recipient, which would induce tolerance irrespective of the donor.

\section{MY RESEARCH AS PART OF MY WORKING GROUP/ RESEARCH TEAM}

This part of my research continued previous works in the field of chronic lung rejection, having demonstrated the compartmentalisation of immune response in transplanted lungs [2] and the importance of T-regulatory (Treg)-cell activation in stable chronic rejection [3].

My research also investigates chronic asthma with the same kind of approach. I developed a model of ex vivo T-cell stimulation with house dust mite-purified allergens and, in this context, studied T-cell activation with regard to T-helper cell (Th) type 1, Th2 and Treg-cell activation. I also monitored the modulation of T-cell co-receptor expression according to the presence of allergy and/or asthma.

\section{THE IMPACT OF MY WORK ON CLINICAL OR RESEARCH PRACTICE}

Our results in lung chronic rejection led us to envisage prospective surveys, including a large number of patients, to detect some biological characteristics and features determining the occurrence of BOS. In the future, we will address the following questions. 1) Does T-reg-cell activation predict the stabilisation of BOS? 2) Do the characteristics of dendritic cell-T-cell interactions predict the long-term tolerance of lung transplant?

In the longer term, the rationale for therapeutic interventions, including cellular therapies with T-regulatory cells or immature dendritic cells will be investigated.

\section{REFERENCES}

1 Reynaud-Gaubert M. Pathophysiology of obliterative bronchiolitis in lung transplants. Rev Mal Respir 2003; 20: 224-232.

2 Mamessier E, Milhe F, Badier M, Thomas P, Magnan A, Reynaud-Gaubert M. Comparison of induced sputum and bronchoalveolar lavage in lung transplant recipients. J Heart Lung Transplant 2006; 25: 523-532.

3 Mamessier E, Lorec A, Thomas P, Badier M, Magnan A, Reynaud-Gaubert M. T regulatory cells in stable posttransplant bronchiolitis obliterans syndrome. Transplantation 2007; 84: 908-916. 